\title{
DESIGUALDADES SOCIAIS \\ E A EDUCAÇÃO ESCOLAR
}

\author{
LES INÉGALITÉS SOCIALES \\ ET L'ÉDUCATION SCOLAIRE
}

Suze Scalcon*

Resumo: Neste artigo é realizada uma discussão em torno do papel que vem sendo desempenhado pela escola mediante o princípio fundamental que ordena a sociedade de mercado: o da desigualdade natural entre os homens. Para tanto, contextualizamos a temática "Desigualdades Sociais e a Educação Escolar" no entorno da reestruturação produtiva do capital, da sociedade de mercado e dos interesses dos setores dominantes em vista da formação humana operada pela escola. Ao discutimos sobre a necessidade da sociedade capitalista, tanto de produzir e reproduzir as desigualdades de classe, como de incluir simbolicamente os desafortunados, problematizamos os conceitos de diferença e desigualdade, e argumentamos sobre o modo através do qual a educação escolar e a pobreza da escola promovem desigualdades. Salientamos o caráter de afirmação e da negação da escola aliado ao caráter destrutivo e amoral do capitalismo expresso pelo estímulo ao carecimento egoísta de bens, quando a escola não se opõe aos direitos exclusivos dos homens privados e à comercialização da humanidade dos indivíduos.

Palavras-chave: Desigualdade. Desigualdades sociais. Naturalização das desigualdades. Educação escolar. 
Résumé: Dans cet article nous présentons une discussion sur le rôle joué par lécole à travers le principe fondamental qu’ordonne la société de marché: l'inégalité naturelle chez les hommes. Pour cela, nous contextualisons le thème des "inégalités sociales et léducation scolaire " autour de la restructuration du capital, de la société de marché et des intérêts des secteurs dominants pour la formation des hommes par lécole. Lorsque nous avons discuté de la nécessité pour la société capitaliste de produire tant que de reproduire les inégalités de classe, en y incluant aussi symboliquement les défavorisés, nous problématisons les notions de différence et d'inégalité et argumentons sur le mode par lequel l'enseignement scolaire et la pauvreté de l'école promeuvent des inégalités. Nous avons mis en évidence le caractère d'affirmation et de déni de lécole associé au caractère amoral et destructif du capitalisme par la stimulation des besoins égoïstes de biens, quand lécole ne soppose pas aux droits exclusifs pour les hommes privés, et la commercialisation de l'humanité des individus.

Mots-clés: Inégalités. Inégalités sociales. Naturalisation des inégalités. Léducation scolaire. 


\section{Introdução}

A educação escolar como uma manifestação contraditória e condicionada pelo desenvolvimento das forças produtivas e pelas transformações objetivas operadas pelo homem na natureza, na sociedade e pela cultura, assim como a educação na vida cotidiana, são práticas sociais historicamente estabelecidas. Como práticas sociais localizadas no tempo e no espaço são determinadas pelas relações propriamente capitalistas instaurando uma sociedade cindida em classes distintas e desiguais; de proprietários e não proprietários, trabalhadores e não trabalhadores, opressores e oprimidos.

Localizamos a abordagem de nossa temática mediante o mais novo processo de reestruturação produtiva do capital e de seus ideários e valores o qual, mais do que nunca, evoca um tipo de formação social estruturada na relação trabalho-capital desenhando diferentes posições ocupadas pelos sujeitos na configuração do todo social, ou seja, no modo de produção. Entretanto, vale dizer que "todos, indistintamente, são parte deste sistema [...]" (GARCIA, 2005, p. 10).

Em face desta nova reestruturação do sistema de acumulação $^{1} \mathrm{a}$ relação trabalho- educação aparece intrinsecamente ligada por um mesmo processo: o processo de formação humana. Considerando a necessidade de formar homens e mulheres para o mundo do trabalho numa sociedade em que o mercado é o eixo das relações sociais (SANFELICE, 2001) - marcadas pela centralidade do traba1 ho ${ }^{2}$ - o trabalho é seu elemento estruturante (ANTUNES, 2004).

Diferente do que pensam autores como Offe (1989), Gorz (1982), Habermas (1972) e Kurz (1992), os quais vêm difundin- 
do a ideia de que o trabalho teria deixado de ser a categoria sociológica central e, assim, caminharia para o seu esgotamento ou mesmo que estaríamos numa era do fim do trabalho e da classe trabalhadora, acreditamos que enquanto vivermos sob a égide do capitalismo indiscutivelmente o trabalho terá valor essencial.

Neste entorno a formação humana vem sendo objeto de preocupação de diferentes forças sociais e institucionais, uma vez que a sociedade capitalista ao procurar superar as contradições geradas pelo colapso do modelo Taylorista-Fordista de produção, ensejou a consolidação de um novo projeto societário, o qual vem reeditar um antigo agora numa versão tão ampliada que capaz de ultrapassar as fronteiras do tempo e do espaço.

A formação de homens, mulheres e crianças, do ponto de vista dos interesses do capital, é uma preocupação central no âmbito das condições necessárias para a dominação, coerção e alienação em vista à manutenção da ordem social e à divulgação de novas formas de ser, estar e pensar diante da realidade.

As transformações ocorridas com o capitalismo em nível mundial nas últimas décadas motivaram reflexões sobre o papel da educação nos meios escolares e acadêmicos em face das orientações das políticas sociais em curso com especial destaque às educacionais.

Em tal contexto, destaca-se a formação de uma conjuntura que conforma a produção do conhecimento (MORAES, 2004), quando na produção acadêmica é introduzido um sistema de pensamento pautado no que se denominou de crise das ciências ou crise dos paradigmas da razão em função da divulgação de uma nova racionalidade científica. Tal denominação é atribuída, pelo pensamento pós-moderno ${ }^{3}$, a um momento de negação da existência 
da objetividade científica e da afirmação de uma subjetividade que privilegia o universo privado em detrimento do universo público, passando-se a falar, entre outros, em multiculturalismo, respeito às diferenças e não mais em classes sociais.

Da mesma forma como as concepções neoliberais e neocapitalistas, o pós-modernismo traz a marca de uma suposta realidade estruturalmente nova, de uma nova sociedade (SAVIANI, 1991, p. 19), cuja ideologia:

[...] tende a situar este período como correspondendo ao período em que a própria estrutura de classe se alterou. Assim não haveria mais a oposição fundamental do capitalismo entre a classe burguesa ou a classe dos capitalistas, de um lado, e o proletariado de outro porque, segundo esta ideologia neoliberal, o capitalismo ter-se-ia socializado.

Este seria um momento de crise nas ciências sociais e na filosofia, no qual aparecem propostas teóricas e metodológicas que “[...] expressam a crise de confiança e a falência de uma determinada concepção de razão: a chamada razão moderna de corte iluminista. Razão que imaginou ser possível fundar o conhecimento circunstanciado, racional, firmemente ancorado em fatos." (DUAYER; MORAES, 1998, p. 63). É a partir da difusão de uma concepção epistemológica eminentemente pragmática, favorável aos interesses dominantes do capitalismo que são centrados esforços ideológicos públicos e privados na direção da formação do homem em vista a constituição de um novo mundo do trabalho.

Em tal contexto, a globalização ${ }^{4}$ da economia, não como um conceito, mas como um construto ideológico (CASTRO, 2001) cuja conotação não somente se expressa no sentido de falseamento da realidade, mas também como uma realidade operante e objeti- 
va, é elemento determinado e determinante de um conjunto de processos vinculados tanto às mudanças nas condições gerais do processo produtivo como na sociedade de um modo geral.

Afirma Castro (2001) que tal elaboração, ao procurar escamotear o sentido social das mudanças que ocorrem na sociedade e na vida das pessoas, oculta "[...] o significado de mudanças econômicas e políticas que, de fato, são socialmente regressivas porque colocam a sociedade e o Estado a serviço exclusivo da economia, ou melhor, do capital financeiro.” (CASTRO, 2001, p. 30).

Na opinião de Noronha (2002, p. 35), para os pós-modernistas:

O 'sistema' - uma vez que o capitalismo, ao se globalizar, criou espaços difusos e desorganizados - não permite um ponto de partida estrutural (modo de produção) para a compreensão da realidade e para a produção do conhecimento. A consequência deste modo de pensar é a tendência a analisar a realidade de forma anistórica, fragmentária e sem relações, onde o individualismo em todos os níveis suplanta os interesses comuns e de classe.

O processo de globalização que eclodiu no início do milênio é considerado por Motta (2008) como bastante problemático devido às consequências por ele deflagradas de modo principal, mas não exclusivo, nos países de capitalismo dependente. Para a autora:

O regime de acumulação do capital introduzido predominantemente a partir dos anos 70, que combina a hipertrofia financeira, 'doutrina' neoliberal e o novo padrão tecnológico de produção e organização do trabalho, provocou mudanças substanciais que resultaram no aumento da pobre$z a$, do desemprego e do subemprego e na precarização do trabalho. (MOTTA, 2008, p. 550, grifo nosso). 
É para este circuito é que a escola é chamada a participar.

As políticas para a Educação Básica dos anos de 1990, elaboradas a partir de acordos estabelecidos entre o Brasil e organismos internacionais regionais, mundiais e hemisféricos, são oriundas de compromisso assumido pelo país em promover medidas capazes de elevar os índices de acesso e permanência de crianças, jovens e adultos à escola em troca de financiamentos. Como partícipe de um conjunto de reformas sociais ${ }^{5}$ mais amplas, tais políticas operacionalizam reformas educacionais que procuram imprimir um caráter salvacionista à educação, tanto no que se refere ao combate de problemas sociais como de problemas econômicos.

No caso da reforma da Educação Básica no Brasil, esta busca adequar a formação das novas gerações às exigências postas pelas transformações no mundo do trabalho, por meio do investimento na formação de professores, posto que formar o professor é formar o trabalhador. Conforme o Conselho Nacional de Educação trata-se da necessidade de que: "[...] o futuro professor experiencie, como aluno, durante todo o processo de formação, de atitudes, modelos didáticos, capacidades e formas de organização que se pretende venham a ser concretizadas nas suas práticas pedagógicas." (BRASIL, 2001, p. 17).

Sob tais circunstâncias é que a educação e seu caráter redentor sobressaem-se numa ambiência de interesses de homens de negócios que contam com a força e o poder do Estado capitalista para garantir a manutenção de seus privilégios de classe.

Em documento intitulado Educación y conocimiento: eje de la transformación productiva con equidad (CEPAL; UNESCO, 1992) destaca-se uma iniciativa que procura: “[...] esbozar lineamientos para la acción en el ámbito de las políticas e instituciones que pue- 
den favorecer las vinculaciones sistémicas entre educación, conocimiento y desarrollo, tomando en cuenta las condiciones existentes en el decenio de 1990." (1992, p. 2).

Em 2004 estes mesmos organismos ao tecerem um panorama da situação educativa em relação à gestão e o financiamento para a América Latina e Caribe afirmam que:

La CEPAL y la UNESCO han venido sosteniendo desde hace más de una década que la educación es el media privilegiado para asegurar un dinamismo productivo con equidad social, fortalecer democracias mediante la promoción del ejercicio ampliado y sin exclusiones de la ciudadanía, avanzar a mayor ritmo en la sociedad de la formación y el conocimiento, y enriquecer el diálogo entre sujetos de distintas culturas y visiones de mundo. (CEPAL; UNESCO, 2004, p. 1).

Observamos com isso que estes organismos se atêm ao empreendimento e à efetivação de ações voltadas à solução de problemas econômicos e ao apaziguamento de conflitos sociais passando a atribuir ao trabalho educativo escolar o imperativo de contribuir para a solução de problemas sociais em favor de um desiderato de natureza econômica.

Shiroma e Evangelista (2011) alertam para o fato de que os problemas econômicos não são produtos do campo educacional e nem mesmo oriundos do trabalho do professor e asseverarem que:

Como se sabe, tais problemas se originam nas relações capitalistas de produção e é nesse âmbito que podem encontrar a sua solução. Certamente a escola tem uma contribuição a oferecer, entretanto não pode ser responsabilizada nem pela produção de desigualdades de classe nem 
por sua supressão. No discurso governamental o papel da escola e do professor foi projetado para que atue na construção de consenso, tolerância, inclusão, paz. (SHIROMA; EVANGELISTA, 2011, p. 147).

As autoras, ao procederem a uma discussão em torno das reformas educativas e das justificativas para a instituição de políticas de profissionalização docente no sentido de aferi-las com a criação de instrumentos avaliativos, consideram que “[...] temáticas emergentes como inclusão, diversidade étnico-racial, desigualdade de gênero, violência, TIC, 'bullying', drogas, educação ambiental, eram insuficientemente abordadas na formação inicial." (SHIROMA; EVANGELISTA, 2011, p. 130).

Neste sentido, Shiroma e Evangelista (2011) ao julgarem que se trata de elementos, de temas que, amplamente divulgados pelas mídias, visavam atestar a despreparação dos professores, de modo que "[...] tanto professores da ativa, quanto instituições de formação foram alvos de um discurso oficial e acadêmico que lhes atribuía responsabilidade pelas mazelas da educação. Professores e formadores foram levados ao banco dos réus." (SHIROMA; EVANGELISTA, 2011, p. 131).

É nesta direção que a escola é chamada mais uma vez pelo Estado a reformar-se de modo que contribua com alguma parcela para o crescimento da economia de mercado. E é chamada dado as crenças instituídas em torno de seu (suposto) poder de transformação social. Transformação a ser operada pelo apaziguamento de conflitos, disseminação de consensos, amenização de mazelas e de uma educação que garanta os desígnios econômicos da civilização, uma educação para o "conformismo social" (GRAMSCI, 2000). 


\section{Sociedade e desigualdades}

O fundamento jurídico da sociedade capitalista, ancorado no direito positivo - o qual o protege e defende o homem mediante aquilo que lhe é privado (liberdade, posses, vida, saúde) - ao sustentar a defesa da individualidade humana, no sentido de que sejam respeitadas diferenças (culturais, de raça, cor, etnia, condições de vida material, classe social etc.), funda-se numa concepção que toma o princípio da desigualdade humana enquanto condição natural de vida e o capitalismo como a única forma de organização social possível.

No caso da individualidade na passagem do feudalismo para o capitalismo Jacomeli e Xavier (2003, p. 196) ao referirem-se aos pilares daquela sociedade consideram que:

O princípio da individualidade, que enfatiza a noção do único, do particular, como forma de ser histórica do sujeito, também trazia consigo a concepção da diferença natural ente os homens, que legitimaria posteriormente as desigualdades sociais geradas pela dominação capitalista.

O liberalismo como doutrina econômica do capitalismo, em sua versão neo, fundada na liberdade individual, ou no direito à vida baseado no respeito às desigualdades de condições materiais e espirituais de existência humana, ao estruturar as regras e leis que devem reger a vida, visa impreterivelmente uma formação humana compatível com os interesses da acumulação capitalista. De outro modo, vale dizer que os homens possuem uma existência ancorada na desigualdade de classe que, tomada como essencial e natural, justifica a existência marcada por diferenças sociais, materiais e psicológicas. 
Neste sentido, Sanfelice (1999, p. 153) considera que em relação aos indivíduos,

[...] a desigualdade natural entre eles é o pressuposto fundamental, necessário para que haja entre eles o equilíbrio e complementação de funções, uma vez que cada um possui capacidades naturais que lhe permite desenvolver-se auxiliado por doses de instinto, somadas a sua racionalidade, vontade e desejos. Os indivíduos são então resultados da sorte.

Entendendo a desigualdade enquanto um valor positivo é que à sociedade de mercado interessa investir numa formação humana apoiada da defesa do respeito às diferenças de modo a controlar processos de constituição de condições de existência, subjetivas e objetivas que, em última análise, são determinantes do perfil e das qualidades necessárias para a reprodução da sociedade capitalista.

Do que decorre o imperativo de uma formação humana que, sustentada no trabalho alienado, enseja um perfil de trabalhador competente à realização de múltiplas tarefas, entretanto, num escasso mercado de trabalho cuja justificativa para o desemprego centra-se na ausência de condições e habilidades naturais dos candidatos aos seus postos.

É em benefício destas condições que se origina a noção de inclusão social associada à de diversidade e diferenças. Noção que no Brasil se expressa nas denominadas Políticas de Educação Inclusiva ${ }^{6}$, não como um reconhecimento por parte de governos mais ou menos interessados em atenuar problemas sociais, mas de uma necessidade plangente do capital mediante uma etapa de revigoramento de sua hegemonia perante mais uma crise e contradições por ele engendradas, entre as quais destacamos a miséria absoluta de um contingente populacional cada vez maior. 
O governo brasileiro a partir da implementação do Programa de Educação Inclusiva: direito à diversidade (BRASIL, 2005) e do Informe Nacional El desarrollo de la educación. inclusiva: el camino hacia el futuro (BRASIL, 2008b) apresentado à UNESCO, na Suíça passa a tomar a noção de educação inclusiva como diretriz educativa nacional.

Garcia (2004), ao realizar um estudo das políticas públicas de inclusão no contexto das determinações econômicas em que se inscrevem, defende a tese de que "[...] as políticas de inclusão propostas não superam as condições de desigualdade social e educacional instaladas sob a lógica do mercado." (GARCIA, 2004, p. 21). Michels (2006), através de pesquisa desenvolvida sobre política educacional nos anos de 1990, concluiu que "[...] a Educação Especial está incluída na reforma educacional nos anos de 1990, entretanto subjaz a ela o desígnio da exclusão. Na verdade, ela possui forte caráter segregador [...]." (MICHELS, 2000, p. 6).

Nota-se que as autoras alertam para a existência de um conjunto de elementos maiores que envolvem as propostas de inclusão, $o$ que torna necessário uma compreensão, cada vez maior, do universo do qual as políticas para a Educação Inclusiva fazem parte bem como, de seu processo embrionário.

Shiroma (2002) no contexto das discussões sobre exclusão social, ao investigar o modo como a noção de inclusão funciona como engrenagem para as políticas econômicas, afirma que:

A introdução dessa expressão no vocabulário da política social ocorreu nos governos socialistas franceses nos anos de 1980, quando foi amplamente utilizada para referenciar grupos de pessoas que viviam às margens da sociedade e, em particular, sem acesso ao sistema de seguridade e benefícios sociais. (SHIROMA, 2002, p. 3). 
Considerando que conceitos como exclusão social, cidadania, qualidade e autonomia, pertenciam ao programa da oposição nos anos de 1980, destaca Shiroma (2002) que os mesmos nos anos de 1990 passam a ser bandeiras da situação, estando presentes nos discursos de empresários, governos e organismos internacionais. Trata-se de conceitos que, outrora antagônicos, nos anos de 1990 emergem como "justapostos e complementares", o que pode ser evidenciado em documentos da Comissão Econômica para a América Latina e Caribe (CEPAL, 1990, 1992) ${ }^{7}$.

Em estudo ${ }^{8}$ sobre a profissionalização de educadores a autora localizou na literatura a existência de diferentes interpretações ${ }^{9}$ sobre exclusão social. Uma referente à identificação de exclusão como pobreza (EUROPEAN COMMISSION, 1994), outra para a qual a exclusão social é decorrente de adultos que não possuem trabalho e de crianças desprovidas de educação decente (LEVITAS, 1998).

Shiroma (2002) cita três tipos ideais de discursos associados à exclusão e inclusão, os quais são identificados por Levitas (1998): o discurso redistribucionista, que toma como preocupação principal a pobreza, e cuja redução estaria na redistribuição da riqueza; o discurso integracionista que teria como causa principal da exclusão o desemprego, e a inclusão operada a partir da criação de possibilidades de empregabilidade através do trabalho remunerado e outro discurso que, apoiado na ideia de subclasse, ressalta aspectos comportamentais e morais de excluídos (crime, delinquência, vícios e maus-hábitos) e a deficiência cultural, sugerindo políticas destinadas ao restabelecimento do cidadão.

Observamos com isso que as desigualdades que procuram ser atenuadas via educação, são desigualdades históricas e sociais e não naturais como se impõe ideologicamente na atualidade. Assim, a inclusão ao modo como as políticas sociais preconizam ja- 
mais ocorrerá de fato, fundamentalmente porque a sociedade capitalista se mantém em função das diferentes posições ocupadas pelos sujeitos no todo social, ou seja, diferentes posições representadas pelas classes sociais e suas desiguais condições de acesso às riquezas naturais e, por conseguinte, à provisão da vida material e espiritual. Portanto, não há excluídos.

Deste modo, é preciso que conheçamos as verdadeiras razões que explicam o "trazer à tona" questões e problemas sociais que são produzidos pelo próprio sistema. Para o capital é promovendo "igualdades", simbólicas, que se afastam os riscos de que a luta de classes tome vigor. Entretanto, o que se oculta é a natureza histórica dos problemas. Portanto, há interesse pleno e absoluto em demandar esforços que amenizem a penúria humana e suas consequências sob a justificativa de que se trata de condições naturais, desígnios do destino individual.

\section{Diferenças e desigualdades}

Aparentemente o significado dos vocábulos diferença e desigualdade denominam a mesma coisa. No caso do primeiro, trata-se da qualidade do que é diferente; falta de igualdade ou de semelhança; o que distingue uma coisa de outra. O segundo, por seu turno diz respeito ao caráter, estado de coisas ou pessoas que não são iguais entre si; diferença que denota ausência de proporção, equilíbrio, uniformidade, regularidade.

Entretanto, se ovacionada a expressão "Viva a diferença!" alguns serão seus seguidores e, se "Viva a desigualdade!", de certo em menor número, mãos se erguerão ao alto e vozes a repetirão. Com o exposto atentamos para o fato de que algo há de desseme- 
lhante entre os vocábulos em questão, algo há entre o que é diferente e o que é desigual.

No século XVIII Rousseau, em seu conhecido "Discurso sobre a origem e os fundamentos da desigualdade entre os homens", como um homem a frente de seu tempo, inicia por examinar tal questão efetuando uma distinção entre dois tipos de desigualdade.

Em suas palavras:

Concebo, na espécie humana, dois tipos de desigualdades: uma que chamo de natural ou física, por ser estabelecida pela natureza e que consiste na diferença das idades, da saúde, das forças do corpo e das qualidades do espírito e da alma; a outra, que se pode chamar de desigualdade moral ou política, porque depende de uma espécie de convenção e que é estabelecida ou, pelo menos, autorizada pelo consentimento dos homens. Esta consiste nos vários privilégios de que gozam alguns em prejuízo de outros, como a serem mais ricos, mais poderosos e homenageados do que estes, ou ainda por fazerem-se obedecer por eles. (ROUSSEAU, 1999, p. 51, grifos nossos).

Embora este pensador acreditasse que o homem é naturalmente bom, do que discordamos profundamente - uma vez que o homem é um ser histórico-social que se humaniza e se elabora por meio de relações com o mundo natural e social, diferenciando-se como espécie pela capacidade de transformar a natureza pelo trabalho, por meio de instrumentos por ele mesmo criados e aperfeiçoados ao longo do desenvolvimento histórico humano - sua classificação denota a apreensão radical do sentido implícito na noção de desigualdade cuja conotação associa-se à injustiça.

Ao que parece, a desigualdade difere profundamente do conceito de diferença porque se encontra atrelada ao desenvolvimento histórico, social e cultural da humanidade, razão pela qual seria um des- 
propósito moral ovacioná-la. Já diferença como forma singularíssima de ser no mundo, uma vez naturalizada - quando em verdade não é - tem no respeito ao direito individual privado seu respaldo.

\section{A escola e a produção de desigualdades}

No início do século XXI a escola é chamada mais uma vez a comparecer ao palco. Entretanto, agora, ao palco do mercado mundializado, cujo cenário é revestido pela tessitura de um conjunto de transformações político-econômicas a fim de que desempenhe um velho e novo papel: a aplicação de mecanismos adaptativos e inclusivos, que visam, em última instância, à formação de consumidores. A composição dos atos cênicos apresentam não exatamente uma história já conhecida e sim uma versão adaptada aos tempos neoliberais.

O espetáculo anunciado traz como figurino o "luxo" do mais alto nível de possibilidade de desenvolvimento humano: a cidadania, a emancipação, a ética, a ampla socialização do conhecimento, a possibilidade da plena consciência ecológica e a deflagração definitiva de que se diferenças existem, estas são naturais. Condicionada e orientada pelas políticas estatais que, invariavelmente, são as políticas da classe dominante, a escola como campo de expressão e de reprodução das relações sociais mercantilizadas é convocada para a apresentação de mais um espetáculo mediante a atual etapa de desenvolvimento do processo civilizatório.

A ideologia do liberalismo renovado ao reforçar as diferenças como valor altamente positivo investe na instituição escolar como um aliado fiel, uma vez que, a escola historicamente determinada é, também, determinante. É nesta direção que a sociedade de 
mercado enseja políticas e reformas educativas que nada mais representam do que a reificação de uma perspectiva social, cuja tônica recai sobre a naturalização das desigualdades, operada pelas instituições educativas escolares e profissionalizantes.

A noção de desigualdade traz à lembrança um importante momento histórico, representado pela mudança de interesses da classe burguesa, na França pós-revolucionária. Retomemos! Na fase anterior, pré-revolucionária: quando a plataforma de lutas da burguesia assentava-se na contestação da sociedade vigente, estruturada de modo desigual e sobre cuja desigualdade a dominação do clero e da nobreza era operada, a classe burguesa entendia a desigualdade como não natural, mas histórica; defendendo a igualdade essencial entre os homens, a liberdade e a participação política.

Entretanto, no momento pós-revolucionário, quando a participação dos indivíduos proclamada e prometida começa a entrar em contradição com os novos interesses da burguesia - a quem convinha que a sociedade recém instalada se perpetuasse -, naquele momento, também interessava impedir tal participação nos processos decisórios. Com esta mudança de interesses é que a classe dominante passou a postular outra concepção, segundo a qual, os homens seriam essencialmente diferentes.

Esta passagem traz não só recordações, mas elementos para pensarmos as diferenças e desigualdades mediante a situação presente e futura da escola. Desse modo, se a diferença, melhor, a desigualdade, é o princípio que sustenta os interesses burgueses desde a consolidação do capitalismo, seria ele um princípio a ser superado na sociedade do presente?

A reedição do anúncio da importância do respeito às diferenças de cor, credo, classes, culturais, de opção sexual entre outras, postuladas na contemporaneidade pelas políticas econômicas e 
sociais, denotaria de fato algum interesse que não o de subordinação da sociedade ao capital?

Embora a escola se encontre um tanto distanciada do cumprimento da tarefa de promoção dos indivíduos, na direção do pleno desenvolvimento humano - de seu caráter humanizador - não deixa de cumprir um papel próprio de todo e qualquer processo contraditório no interior da sociedade, qual seja, o de negar a si mesma. E ao negar-se a escola se esvazia e esvaziada sede seu lugar aos sistemas de mídia os quais, ao transformarem o saber objetivo em mensagens e informações fragmentadas, escamoteiam as desigualdades sociais ao mesmo tempo em que, contraditoriamente, difundem a ideia de que todos são iguais.

Motta (2008), analisando as alterações efetuadas nas abordagens de políticas públicas para os países do capitalismo dependente, em particular as materializadas nas Políticas de Desenvolvimento do Milênio ${ }^{10}$, afirma que estas se constituem em:

[...] mecanismos de hegemonia de função de direção intelectual e moral, com ações concretas e definições de metas focadas nas camadas de trabalhadores 'excluídos' do processo produtivo, mas que ainda possuem condições produtivas, para instaurar um processo mais intensivo de educar para o conformismo. (MOTTA, p. 549, grifo do autor).

Nesta direção, Belloni (1998, p. 5) considera que a escola agora é:

[...] apenas mais uma entre muitas agências especializadas na produção e na disseminação da cultura. Em concorrência com as diferentes mídias, a escola tende a perder terreno e prestígio no processo mais geral de transmissão da cultura e particularmente no processo de socialização das novas gerações, que é sua função específica. 
A escola, não mais detentora da função de socializar os conhecimentos e desobrigada da tarefa de promover as formas mais desenvolvidas do saber objetivo, representadas pelo conhecimento científico, acaba por esvaziar e educação escolar de um modo geral. E a esvazia ao ponto de gerar somente alienação através do que veicula, ou seja, conteúdos ditos de ensino transformados em informações e mensagens desarticuladas e provisórias.

Portanto, do mesmo modo como os sistemas de mídia, mas em grande desvantagem, é que a escola vem disputando a manipulação das consciências alienadas que vivem na dependência dos estereótipos "sugeridos" pela moda e uniformizados pela lógica do mercado. Isso pode ser evidenciado pelo fato de que a escola perde espaços quando são fundadas outras agências sociais, como é o caso das organizações não governamentais e de programas assistenciais instituídos pela iniciativa privada, os quais são chamados a ocupar o lugar e o papel do Estado no que compete à implementação de políticas públicas.

Retomemos aqui o caráter contraditório presente no curso do desenvolvimento histórico da escola e, mais propriamente, no âmbito da sociedade. Caráter expresso por sua afirmação e negação como instituição destinada a instruir e formar o homem através da apropriação de conhecimentos.

A escola se afirma por ser uma instituição determinada pelas necessidades criadas pelo desenvolvimento das forças produtivas, na esfera do modo capitalista de produção e cuja tarefa é a transmissão-assimilação do saber produzido socialmente. E socializa este saber ao dar acesso às novas gerações. Entretanto, por um lado, socializa e democratiza o saber, mas, por outro, não o realiza de forma plena, uma vez que as relações sociais a impedem, pois 
é preciso manter as condições necessárias de dominação de uma classe sobre outra, o que ocorre pela apropriação privada do conhecimento por parte da classe dominante. Saviani (1991, p. 81) considera que esta contradição assim se expressa:

O saber produzido socialmente é uma força produtiva, é um meio de produção. Na sociedade capitalista a tendência é torná-lo propriedade exclusiva da classe dominante. Não se pode levar esta tendência às últimas consequências porque isso entraria em contradição com os próprios interesses do capital.

Por conseguinte, a escola é negada pelo fato de somente dar à classe trabalhadora uma fração do saber, algo como o bastante para que a sobrevivência mínima seja garantida e de modo que o trabalhador possa, minimamente, sobreviver, e nunca uma parcela que se aproxime da totalidade do conhecimento socialmente produzido.

O sentido da afirmação e da negação da escola é dirigido por um conjunto de mecanismos ideológicos que procuram escamotear as contradições do capital no que tange a socialização do trabalho e a apropriação privada dos meios e produtos deste trabalho, os quais são operados, fundamentalmente, por um processo de abandono do caráter específico da prática educativa escolar ou a uma tendência a desvalorizar a educação quando, entre outros mecanismos, secundariza o processo de transmissão-assimilação dos conhecimentos.

Neste sentido, a escola torna menos importante o trabalho educativo fundado no trato dos conhecimentos sistematizados, representados pelas diferentes áreas científicas do conhecimento, de modo a centralizar, a tomar como espinha dorsal de seu trabalho ou linha de frente, por exemplo, as datas comemorativas. Trata-se 
de uma prática pedagógica atualmente muito difundida no interior das escolas, algo como uma tendência orientada pela fundamentação do trabalho educativo na lógica do mercado consumidor e, mais do que isso, dirigida para a formação de consumidores.

Na opinião de Leher (1998, p. 235), “[...] a escola elementar é tida como uma instituição centrada mais nos valores e nas atitudes (flexibilidade, atitude favorável ao mercado etc.) do que nos fundamentos do conhecimento científico, artístico e cultural (daí o esvaziamento da formação do professor)."

Em relação às funções da escola, verifica-se uma sobreposição entre políticas sociais e políticas educacionais na medida em que a escola vem se transformando em local de assistência médica, odontológica, alimentação, entre outros. A escola vem perdendo espaço quando são fundadas outras agências sociais chamadas a desempenhar o papel do Estado no que se refere a responsabilidades, como é o caso das organizações não governamentais e de diversos programas de empresas, fundações e de outros setores da iniciativa privada.

Quanto aos processos de transmissão do saber, vinculados à prática pedagógica mesma, observa-se a falta de domínio de alguns elementos fundamentais, para não dizer clássicos do fazer didático, algo como a transformação, por exemplo, dos conteúdos de ensino em um elenco de atividades desarticuladas entre si e das realidades e necessidades históricas de onde se originaram. Os objetivos escolares se expressam por um elenco de ações a serem realizadas pelo professor, quando em verdade os objetivos do ensino são estágios de desenvolvimento psíquico a serem atingidos pelos os alunos; dizem respeito a habilidades intelectivas a serem elaboradas não pelo professor; a metodologia passa a ser uma atitude espontaneísta de distribuição de atividades ou exercícios, copiados 
ou realizados nos livros didáticos; a avaliação, um mecanismo de julgamento, de classificação e de medida do saber.

Desse modo é que, na atualidade, os conhecimentos humanos tendem a ser reduzidos a uma cultura de massa midiatizada, por meio da qual é pretendido, em nome da emancipação humana, manter o controle e a dominação social. Através desta investida ideológica,

[...] é que a escola, orientada por políticas educacionais afinadas com os rumos da sociedade de consumo, assume a inclusão de conteúdos de ensino como aqueles chamados de temas transversais, mediante o argumento do necessário respeito às diferenças individuais; preconiza-se a unificação das culturas sob a égide do que se convencionou chamar de multiculturalismo. (SCALCON, 2010, p. 287).

Note-se bem que, ao mesmo tempo em que a escola é chamada a desempenhar um novo papel em direção à construção de uma sociedade do conhecimento, numa perspectiva de afirmação, abandona suas formas mais peculiares e específicas de difundi-los, caminhando na perspectiva de sua própria negação.

Cabe ainda questionar se o propalado papel emancipador, do qual se reveste a denominada "era da sociedade do conhecimento", não estaria referido à deflagração de uma sociedade que assume como utopia a possibilidade de desenvolvimento humano fundado na cidadania, na ética, na socialização do conhecimento e na consciência ecológica?

Entretanto, do mesmo modo como cabe questionar, cabe responder: em tempos pragmáticos, a negação da história do gênero humano, fundado no ledo engano de que não mais existiriam classes sociais, é o que as políticas neoliberais pretendem divulgar, enquanto a mais nova ilusão, que agora existiriam espaço para to- 
dos. Ilusão esta que, em negando os ideais socialistas, sugere que estaríamos vivendo as recompensas de um ideal societário que muito tem a dar para todos. Mas se o tem, por que o nega?

É evidente que o capitalismo, ao procurar uma nova forma de sobrevivência e de adequação de sua dinâmica de inserção pacífica na sociedade, o que se alia na atualidade a um produto científico altamente desenvolvido, a informática e, com ela, a alta tecnologia da informação e da comunicação, somente nos faz perceber que estamos vivendo, realmente, outros novos tempos.

Tempos estes que guiados por políticas públicas que longe de emancipar os homens, dando-lhes uma cidadania prometida e socializando os conhecimentos historicamente elaborados, delega à escola o papel missionário de resolver os problemas sociais para que estes não mobilizem rebeliões em massa e pregar o culto à fatalidade dos desígnios da natureza e do destino individual.

\section{A escola promotora de desigualdades}

A escola promove, sim, desigualdades e as promove por não refletir as contradições da sociedade. Porque não agarra com unhas e dentes - e não espalha - o conhecimento mais desenvolvido e rico que a humanidade já produziu histórica, cultural e cientificamente pelo conjunto dos homens. A escola promove desigualdades porque não se atém ao saber objetivo

A escola promove desigualdades porque não rompe com o cotidiano alienado dos alunos, porque não eleva a qualidade do trabalho educativo para além da preocupação com vida experiencial imediata e individual, para além do corriqueiro. 
A escola promove desigualdades porque não opera com um trabalho voltado para a tarefa clássica de transmissão do conhecimento às novas gerações e por cuja especificidade se referendou por séculos; porque na escola as crianças não vêm se apropriando do conhecimento e das formas de compreensão mais desenvolvidas, ricas, amplas e profundas que a humanidade já produziu.

Desigualdades são promovidas pela escola porque não centra suas atividades no estudo da ciência, da arte, da filosofia, naquilo que é sua essencialidade. Quisera a escola do presente ecoasse na vida das crianças como sinos luminosos que, ao balanço de suas sintonias, elevassem os homens e as mulheres à condição de seres de domínio de seus próprios destinos.

A desigualdade natural entre os homens é promovida pela escola porque ela está afastada da riqueza do que poderia ser a vida das pessoas, diante do acúmulo e desenvolvimento de conhecimentos que a humanidade produziu. A escola está mais próxima da vida limitada e alienada do nosso cotidiano, excessivamente próxima daquilo que o capitalismo tem produzido de pior. Precisamos de uma escola que produza mudanças na vida dos indivíduos a partir de noções mais elevadas, de novas necessidades, fundamentalmente mais importantes do que aquelas geradas pelo mercado consumidor; de uma escola que promova o desenvolvimento de formas de linguagens desconhecidas, não naturais, daquelas que façam com que os alunos avancem na direção do desconhecido. $\mathrm{O}$ trato com a linguagem rudimentar não fomenta o domínio da língua materna; promove, dirige e aprisiona os futuros em senzalas repletas de troncos, cujas raízes fincadas em glebas privadas, de somente alguns, fazem nascer dias tristes, torpes, pobres e, pior, eternos presentes. 
Há um caráter destrutivo e amoral próprio do capitalismo o qual é promovido quando do estímulo ao carecimento egoísta de bens, não tão bons, o que tem sido instigado pela escola quando esta se posiciona em favor dos direitos egoístas dos homens privados e à comercialização da humanidade dos indivíduos. E se posiciona porque a nada se opõe.

A escola que ao ensinar a seus alunos o convívio fraterno e tolerante com a pobreza da cultura, com a miséria da filosofia, com a negação da ciência e com a ignorância sobre o valor da arte, corrobora com um estado de plena subserviência aos ditames daquele tomado como um só e único senhor: o capital.

Precisamos não de uma escola que ensine a comemoração e o aplauso à lógica estritamente econômica, mas de uma que eleve a formação humana a compreensões que superem estados patéticos de alienação e de egoísmo.

Mas e o futuro da escola? O futuro está condicionado à capacidade de reunião das forças sociais na direção de uma "estratégia de resistência ativa" (SAVIANI, 1994) e de elaboração de um projeto de formação humana apoiado na convicção de que a história é, antes de tudo, cenário cujo palco ainda está por ser armado.

Entre dramas, tragédias, comédias e tramas é preciso ter clareza de que: "A luta popular hoje deve ser anticapitalista" (FONTES, 2009), porque o que não se transforma no presente não se objetiva no futuro, uma vez que "[...] novas relações de produção mais adiantadas jamais tomarão o lugar, antes que suas condições materiais de existência tenham sido geradas do seio mesmo da velha sociedade." (MARX, 1978, p. 130). 


\section{Referências}

ANTUNES, Ricardo. Adeus ao trabalho? Ensaio sobre as metamorfoses e a centralidade do mundo do trabalho. 9. ed. São Paulo: Cortez, 2004.

BELLONI, Maria Luiza. O que é sociologia da infância. Campinas: Autores Associados, 2009.

BRZEZINSKI, Zbigniew. Between two ages america's role in the technetronic era. Nova York, 1969.

BRASIL, CNE. Câmara de Educação Básica. Resolução n. 2, Diretrizes Nacionais para a Educação Especial na Educação Básica, de 11 de setembro de 2001. Brasília, 2001.

BRASIL. Programa de Educação Inclusiva: direito à diversidade. Documento Orientador. Brasília, DF: MEC; SEEsp., 2005. Disponível em: <http://portal.mec.gov.br/seesp/arquivos/pdf/orientador1.pdf > . Acesso em: 15 set. 2010.

BRASIL. MEC. SEESP. Política Nacional de Educação Especial na Perspectiva da Educação Inclusiva. Brasília, janeiro 2008a.

BRASIL. MEC. Informe Nacional de Brasil. El desarrollo de la educación. Educación inclusiva: el camino hacia el futuro. $48^{\text {a }}$ Sesión de la Conferencia Internacional de Educación. Ginebra - Suiza, del 26 al 28 de noviembre del 2008, 2008b.

CASTRO, Ramón Peña. Critica da globalização como ideologia economicista do capitalismo total. In: LASTÓRIA, da Costa; PUCCI, Bruno (Orgs.). Teoria crítica, ética e educação. Campinas: UNIMEP/ Autores Associados, 2001. p. 29-44.

CEPAL/UNESCO. Educación y Conocimiento: eje de la transformación productiva con equidad. Santiago do Chile, 1992.

DUAYER, Mario; MORAES, Maria Célia Marcondes de. História, estórias: morte do "real" ou derrota do pensamento? Perspectiva, Florianópolis, v. 16, n. 29, p. 63-74, jan./jun. 1998. 
FONTES, Virginia. A luta popular hoje deve ser anticapitalista. Caros Amigos, 2009. Entrevista. Disponível em: <http://issuu.com/ carosamigos/docs/leitores150>.

FOUCAULT. Michael. Microfísica do poder. Rio de Janeiro: Graal, 1970.

GARCIA, Adir. Valdemar. A Pobreza do homem. 2005. Tese (Doutorado)

- Programa de Pós-Graduação em Sociologia Política, Universidade Federal de Santa Catarina, Florianópolis, 2005.

GORZ, André. Adeus ao proletariado. Rio de Janeiro: Forense, 1982.

GRAMSCI, Antonio. Cadernos do cárcere, vol 3: Maquiavel. Notas sobre o estado e a política. Edição e tradução Carlos Nelson Coutinho. Rio de Janeiro: Civilização Brasileira, 2000.

HABERMAS, Jürgen. Toward a rational society. Londres: Heinemann, 1972.

HARVEY, David. Condição pós-moderna. Uma pesquisa sobre as origens da mudança cultural. 18. ed. Tradução: Adail Ubirajara Sobral e Maria Stela Gonçalves. São Paulo: Loyola, 2009.

JACOMELI, Mara Regina Martins; XAVIER, Maria Elizabete. A consolidação do liberalismo e a construção da ideologia educacional liberal no Brasil. Associados/HISTEDBR/UnC, 2003, p. 195-208.

KURZ, Robert. O colapso da modernização: da derrocada do socialismo de caserna à crise da economia mundial. São Paulo: Paz e Terra, 1992.

LEHER, Roberto. Da ideologia do desenvolvimento à ideologia da globalização: e educação como estratégia do banco mundial para "alívio" da pobreza. 1998. Tese (Doutorado) - Faculdade de Educação, Universidade de São Paulo, São Paulo, 1998.

LIMA, Kátia Regina de Souza. A política de ensino superior a distância no Brasil nos anos de neoliberalismo. Perspectiva, Florianópolis, v. 29. n. 1, p. 19-47, jan./jun. 2011. 
MACLUHAN, Marshall. War and piece in the global village. Nova York, 1968.

MORAES, Maria Célia Marcondes de. Incertezas nas práticas de formação e no conhecimento docente. Texto para mesa redonda "Políticas de formação de professores", II Congresso Luso-Brasileiro de Estudos Curriculares. Anais... Rio de Janeiro: 17 a 20 de agosto de 2004.

MARX, Karl. Manuscritos econômico-filosóficos e outros textos escolhidos. São

Paulo: Abril Cultural, 1978.

MOTTA, Vânia Cardoso da. Ideologias do capital humano e do capital social: da integração à inserção e ao conformismo. Trabalho, Educação e Saúde, 2009. Disponível em: <http://www.revista.epsjv.fiocruz.br/ upload/revistas/r225.pdf>.Acesso em: 14 fev. 2013.

NORONHA, Olinda Maria. Políticas neoliberais, conhecimento e educação. Campinas: Alínea, 2002.

OFFE, Claus. Trabalho como categoria sociológica fundamental? Trabalho \& Sociedade. Rio de Janeiro: Tempo Brasileiro, 1989. v. I.

PRIEB, Sérgio. A problemática do trabalho no capitalismo avançado. In: PRIEB, Sérgio. $O$ trabalho à beira do abismo: uma crítica marxista à tese do fim da centralidade do trabalho. Ijuí: Editora Unijuí, 2005. p. 167-191.

ROUSSEAU, Jean-Jacques. Discurso sobre a origem e os fundamentos da desigualdade entre os homens. Brasília: Editora Universidade de Brasília; São Paulo: Ática,1989.

SANFELICE, José Luis. O modelo econômico, educação trabalho e deficiência. In: LOMBARDI, José Claudinei. Pesquisa em educação: história, filosofia e temas transversais. Campinas: Autores Associados, 1999. p. 151-159.

Pós-modernidade, globalização e educação. In: LOMBARDI, J. C. (Org.). Globalização, pós-modernidade e educação. Campinas: Autores Associados, 2001. p. 3-12. 
SAVIANI, Dermeval. Educação e questões da atualidade. São Paulo: Cortez, 1991.

- Desafios atuais da pedagogia histórico-crítica. In: SILVA JUNIOR, Celestino Alves da (Org.). Dermeval Saviani e a educação brasileira: o simpósio de Marília. São Paulo: Cortez, 1994. p. 243-286.

SCALCON, Suze. De Trilhas em trilhas: da afirmação à negação da escola. In: ALMEIDA, Maria de Lourdes Pinto; FERNANDES, Sônia Regina Souza (Orgs.). História da educação e da escola: olhares lusobrasileiros. Campinas: Mercado de Letras, 2010. (Posfácio).

SHIROMA, Eneida; EVANGELISTA, Olinda. Avaliação e responsabilização pelos resultados: atualizações nas formas de gestão de professores. Perspectiva, 2011. Disponível em: <http:// www.periodicos.ufsc.br/index.php/perspectiva/article/view/2175795X.2011v29n1p127>. Acesso em: 24 fev. 2013.

Profissionalização do magistério e construção de novo perfil docente. In: V Colóquio de Ciências da Educação, 2004, Lisboa. Separata de resumos. Universidade Lusófona, 2004.

SHIROMA, Eneida. A outra face da inclusão. Teias, 2002. Disponível em: $<$ http://www.periodicos.proped.pro.br/index.php?journal=revistateias\& page $=$ article\&op $=$ view\&path\%5B\%5D=55> Acesso em: 23 jan. 2013.

\section{Notas}

* Doutora em Educação pela Unicamp. Pós-doutora em Educação pela UFSC. Professora do Departamento de Metodologia do Ensino da Universidade Federal de Santa Maria. E-mail: <suzegs@terra.com.br>.

1 "Sistema também denominado de acumulação flexível, cujo conceito segundo Harvey, refere-se à passagem do modo fordista de acumulação capitalista, dominante de 1920 a 1970, juntamente com a política keynesiana que vigorou a partir de 1945, para um modo flexível, como forma de superar a crise do capital, aprofundada a partir do início dos anos de 1970." (LIMA, 2011, p. 39).

${ }^{2}$ Um interessante estudo sobre a negação do fim da centralidade do trabalho no capitalismo contemporâneo é realizado por Prieb (2005) com base em dados relativos à jornada, ao volume e à população trabalhadora a partir dos últimos 25 anos em 13 países. 
${ }^{3} \mathrm{O}$ pós-modernismo é um sistema que veicula novas formas de hegemonia cultural e política. Um fenômeno que procura questionar e desconstruir as ideias iluministas se impondo a partir de concepções de natureza artística, acadêmica, política e econômica que vislumbram uma sociedade de consumo de massa operada pela produção da comunicação altamente informatizada a partir de uma intensa utilização de símbolos e imagens voltados para a intensificação da percepção estética. Na produção acadêmica é introduzido um sistema de pensamento pautado no que se denominou de crise das ciências em função da divulgação de uma nova racionalidade científica pela negação da objetividade e afirmação de uma subjetividade que privilegia o universo privado em detrimento do universo público, passando-se a falar em cultura de massa e não mais em classes sociais. Os elementos essenciais da doutrina pósmoderna podem ser encontrados em Foucault (1970); Harvey (2009).

${ }^{4}$ A origem do termo globalização juntamente com a expressão sociedade global data do final dos anos de 1960 do século XX tendo sido cunhadas por MacLuhan e Brzezinski nas obras Guerra e paz na aldeia global (1968) e O papel dos EUA na era da microeletrônica (1968), respectivamente.

${ }^{5}$ Entre tais reformas estão a da previdência, da saúde, da educação, fiscal, tributária, habitacional, econômica, entre outras.

${ }^{6}$ Tais políticas encontram expressão na Resolução n ${ }^{\circ} 2$ do Conselho Nacional de Educação (CNE) que institui as Diretrizes Nacionais para a Educação Especial na Educação Básica (BRASIL, 2001) e na Política Nacional de Educação Especial na perspectiva da Educação Inclusiva (BRASIL, MEC-SEESP, 2008a). ${ }^{7}$ A CEPAL originária de um amplo movimento em favor da autodeterminação no campo da economia do ponto de vista do crescimento, fundada em 1946 pela iniciativa do economista argentino Raul Prebish. Estruturou-se como grupo preocupado com a possibilidade de ocorrência de rebeliões em face das consequências do avanço das forças produtivas. Disponível em: <http:// educaterra.terra.com.br/voltaire/500br/estatista_privatistas4.htm $>$. Acesso em: 23 dez. 2012.

8 Estudo referente à pesquisa "Profissionalização de educadores: estudo comparado Brasil e Inglaterra", desenvolvida na School of Continuing Education, University of Nottingham, 2000-01, a qual contou com a análise de documentos do Departamento para a Educação e Emprego Inglês.

9 Trata-se de interpretações de sociolinguistas como Norman Fairclough e Ruth Levitas, os quais realizam uma análise do discurso do governo trabalhista britânico.

${ }^{10}$ Os objetivos de Desenvolvimento do Milênio surgem da Declaração do Milênio das Nações Unidas, adotada pelos 191 estados membros no dia 8 de setembro de 2000. Criada em um esforço para sintetizar acordos internacionais alcançados em várias cúpulas mundiais ao longo dos anos 1990 (sobre meioambiente e desenvolvimento, direitos das mulheres, desenvolvimento social, racismo etc.). $<$ http://pt.wikipedia.org/wiki/Objetivos_de_Desenvolvimento_ do_Mil\%C3\%AAnio>. 